\title{
Design of Children's Product Packaging Preference Based on Big Data Machine Learning
}

\author{
Yuan Gao \\ College of Fine Arts and Design, Suzhou University, Suzhou, 234000 Anhui, China \\ Correspondence should be addressed to Yuan Gao; goumiao429@ahszu.edu.cn
}

Received 17 April 2021; Revised 16 June 2021; Accepted 20 July 2021; Published 15 August 2021

Academic Editor: Wenqing Wu

Copyright () 2021 Yuan Gao. This is an open access article distributed under the Creative Commons Attribution License, which permits unrestricted use, distribution, and reproduction in any medium, provided the original work is properly cited.

\begin{abstract}
Children's product packaging is also gaining more and more attention from the society as the hope of the future of the homeland and the most interested groups of the society. However, the current packaging design for children's products is uneven and lacks a good user experience. Therefore, the packaging design of children's products needs to be improved urgently. Therefore, this article uses big data and machine learning technology to first investigate the packaging preferences of children's products, and on this basis, designs a product packaging style that is more in line with the current children's preferences and needs, which provides a reference for subsequent related research. In order to find out the preference of children's product packaging under big data machine learning, this article uses the literature method, questionnaire survey method, interview method, experimental method, and other research methods to conduct research on the basis of previous research. The results of the study show that the packaging preferences of children and parents for children's products are mainly affected by the color, type, and material. Children's products of different colors have different attractiveness to children of different ages, and the difference can reach more than $20 \%$. Parents' children's products are mainly affected by the materials and uses of the products, and products that are useful for children's education and growth are more favored by parents. This shows that if companies want to increase the sales of children's products, they need to consider the ideas of children and parents at the same time to achieve their goals.
\end{abstract}

\section{Introduction}

In recent years, with the development of the society, the number of children's products has been increasing in the consumer market and competition is intensifying. As an important visual element of packaging, modeling plays an important role in the design of packaging for children's products [1]. By investigating the current situation of children's product packaging in the domestic and foreign markets, it is analyzed and found that children's product packaging has a trend of simplification. In response to this situation, the application of bionic elements to the packaging of children's products for redesign has not only met children's psychological needs but also played a certain degree of interest. In this context, this article combines the bionic design theory to design the packaging of children's products [2]. Use literature research method, design practice method, case investigation method, and induction verification method for analysis and research. This article combs the consumption characteristics of children and parents and analyzes the relationship between bionic elements and the packaging of children's products. According to the theory of the bionic design, this article is dedicated to summarizing the methods and principles of the bionic design [3].

The problems of modern children's product packaging design have long gone beyond pure sex and physicality. The psychological effects, humanities, and cultural connotations implicit in packaging have long been radiated from the inside out [4]. Packaging is a combination with sociology and aesthetics and has a trend of scientific life and folklore development. The beauty embodied in the packaging of children's products not only represents new culture, new information, and new vitality but also embodies the public welfare and contemporary flavor of the product packaging culture. Relatively speaking, under the influence of the commercial atmosphere of chasing interests and reputation in modern society, packaging of children's products has gradually become a means for businesses to invest and make profits. Therefore, 
potential product safety hazards have appeared in the packaging design of children's products. How to make good use of the role of various elements in product packaging design to promote children's physical and mental development and eliminate potential safety issues as much as possible has gradually become a modern packaging design for children's products, an important task [5].

Among the foreign children's product packaging, the current situation of children's product packaging design is relatively comprehensive compared with domestic development. Kent MP takes advantage of this color rule, starting from the colors of children's preferences, choosing colors with strong contrast, high brightness, and brightness as the main colors of children's product packaging, increasing the popularity of products, and promoting sales [6]. Signal LN believes that the most innovative and attractive products can be designed through the rich, vivid, and interesting expressions displayed by the graphics. The graphics can directly express the information of the product and will increase the interest of the packaging [7]. In China, Li Yibin proposed that more attention should be paid to the design function of packaging. Continuously developing, creating, and innovating design concepts and ideas, while accurately conveying product packaging information, can not only guide new consumption concepts but also continuously acquire, inspire, and use new ideas, which will subtly influence the development of children's minds [8]. Yang Xianyi explored and analyzed the art design from different perspectives such as design history, morphology, and aesthetics. He examined and evaluated the influence and significance of the design from multiple angles and all rounds. However, he did not discuss the specific methods of design in detail. The research in this paper provides directions [9]. Zhao Tingting studied the "color," "function," and "texture" of different organisms and found relevant design elements that can be applied to food packaging and to better imitate and apply natural elements in food packaging. Make food closer to nature. From the imitation of food packaging, summing up consumers' aesthetic concepts, it points out the development direction of food packaging and bionics [10]. The problems faced by the packaging design of children's products in China are mainly ignoring the thoughts of children's inner world, not observing things from their perspectives and extracting them for use in the design.

Through the research on the market of children's food packaging and the collection of relevant literature, this paper finds that there are relatively few studies on the design of children's food packaging. Many academic papers and monographs have carried out research on the colors and graphics of children's food packaging. Although the research on children's food packaging design has provided a lot of specific academic theoretical knowledge, it has not made a design performance for children's food packaging and proposed a detailed and systematic methodology. Taking the design system of design methodology as the starting point, combined with relevant theoretical knowledge of the design, aesthetics, etc., an in-depth design analysis of children's food packaging shapes was carried out and practical operability and detailed design techniques and principles were summa- rized and summarized for children's food The design of the packaging shape provides a reference.

\section{Preference Design Methods for Children's Product Packaging}

2.1. Children's Products. With the rapid development of the times, packaging has gradually become a bridge between goods and consumers. The design embodied in packaging is no longer satisfied with its most basic functions and people's consumption in food, clothing, housing, and transportation is gradually increasing. The ground is based on the user experience $[11,12]$. Due to the rapid development of high technology, people have been unable to obtain the slowly missing emotional needs and user experience from the pure "you design and I use" product design concept. In short, its packaging can no longer provide consumers with real user experience and psychological satisfaction. Nowadays, packaging designed based on user experience is increasingly attracting more consumers to buy for the experience. The humanistic thinking brought about by design concepts that are easily accepted by society and enterprises can pave the way for the product packaging design that emphasizes the emotional market in the future. As people's consumption consciousness strengthens and they pursue spiritual needs, a design trend that focuses on aesthetics and uses feedback information from experience to design more humane products has gradually emerged. This design trend can allow people to find their own emotional outlet and enhance the user experience that they obtain when using the product [13].

At the same time, as the society pays more and more attention to the special group of children, the packaging of children's products has followed that people's attention to the packaging of children's products has also increased. Children's physical and mental development is very important; they have their own unique ability to perceive things and ways of communication [14, 15]. Therefore, compared to other types of product packages, designers need to make specific plans for packaging designs for children's products. On the basis of children's user experience, use their feedback information to make targeted and planned improvements and then implement them and get some real and very helpful feedback information from users to further improve the design of product packaging to attract more children, satisfy their curiosity to a greater extent, bring unforgettable experiences, make them have fun, develop their intelligence, and satisfy their physical and psychological needs [16].

Although color is one of the powerful design languages that directly attract children's attention, at the same time, graphics also play an indispensable role. Graphics also make up a large proportion of the packaging of children's products and are also part of the designer's focus on the design. Graphics can directly represent product information, adding interest and personality to the package [17]. Through the rich, vivid, and interesting expressions shown by the graphics, the most novel and attractive products are designed. We investigated the packaging design of some popular children's products, as shown in Figure 1. 


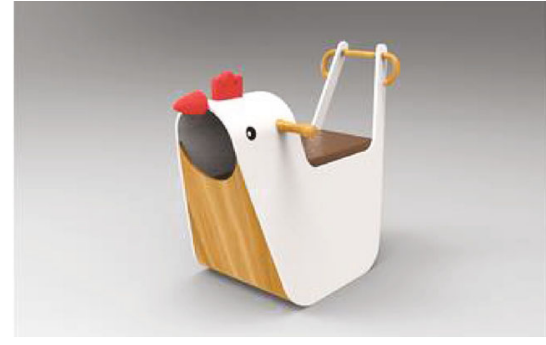

(a)

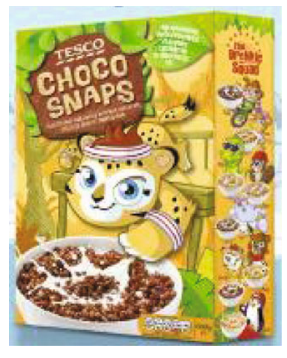

(c)

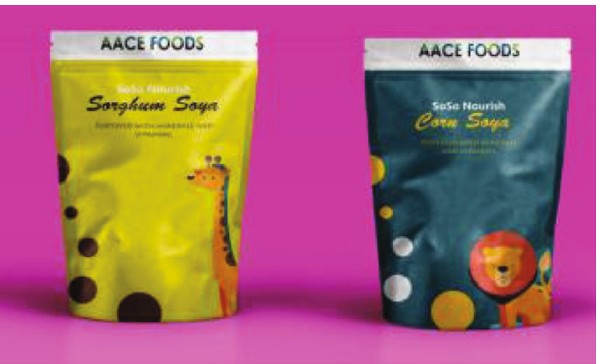

(e)

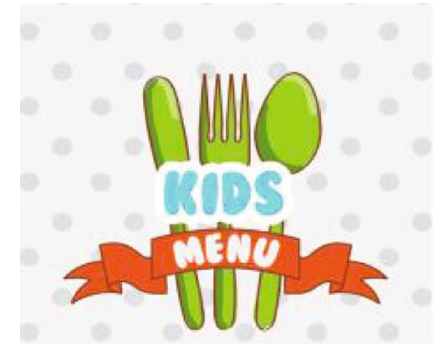

(b)

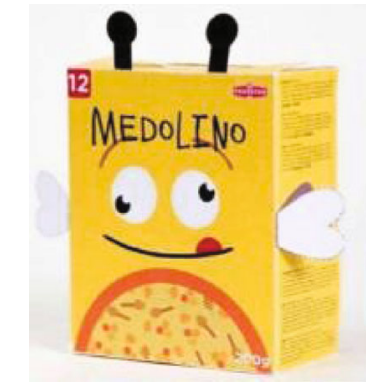

(d)

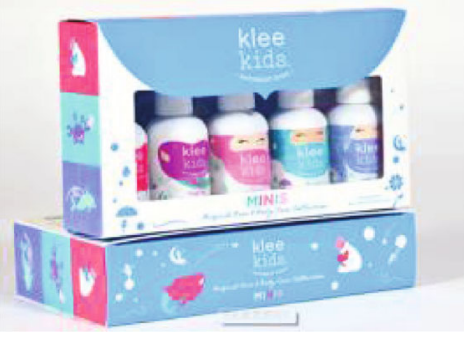

(f)

Figure 1: Popular children's product packaging.

In addition to the two design languages of color and graphics, designers are also good at using the packaging structure. The packaging structure of children's products plays an obvious auxiliary role in improving user experience and increasing interest. Children are more sensitive than rational when choosing their favorite products. In addition to bright colors and interesting patterns, the cute and ingenious structure is also one of the powerful weapons that can attract their attention.

2.2. Big Data. The development of the big data industry is closely related to big data and its applications. Although it originated from industry practice, academic research on the "big data industry" lags far behind the development of practice [18]. From a domestic perspective, the current research on the big data industry is mainly based on government industrial policies and plans, industrial development suggestions, comparisons of domestic and foreign big data industries, and industrial development influencing factors. There is a lack of appropriate theoretical perspectives on the internal big data industry. Research on constituent elements and governance mechanisms; from a foreign perspective, although there are not many related studies, scholars have begun to discuss the big data industry from the perspective of business ecology. Big data is generally achieved through the following methods.

$$
m_{a}=\sum_{b=1}^{n} \lambda_{a b} \vartheta_{a b}
$$

Among them, $m_{a b}$ is the individual's contribution to the overall degree of ordering and $\lambda_{a b}$ is the weight of each order parameter. Therefore,

$$
y\left(k T+t_{i}\right)=\frac{1}{\alpha(z)} \sum_{j=1}^{r} \beta_{i j}(z) \bar{u}\left(k T+t_{j-1}\right)+v\left(k T+t_{i}\right),
$$

which can be transformed into

$$
\begin{array}{r}
\alpha(z)=1+\alpha_{1} z^{-1}+\alpha_{2} z^{-2}+\cdots+\alpha_{n} z^{-n}, \\
\beta_{i j}(z)=\beta_{i j}^{0}+\beta_{i j}^{1} z^{-1}+\beta_{i j}^{2} z^{-2}+\cdots+\beta_{i j}^{n} z^{-n} .
\end{array}
$$

Its function $s\left(k T+t_{i-1}\right) i=1,2, \cdots, r-1$ is to move the sampling signal $s\left(k T+t_{i-1}\right)$ in time backward by 1 nonuniform sampling interval, and a new transfer function model is proposed: 


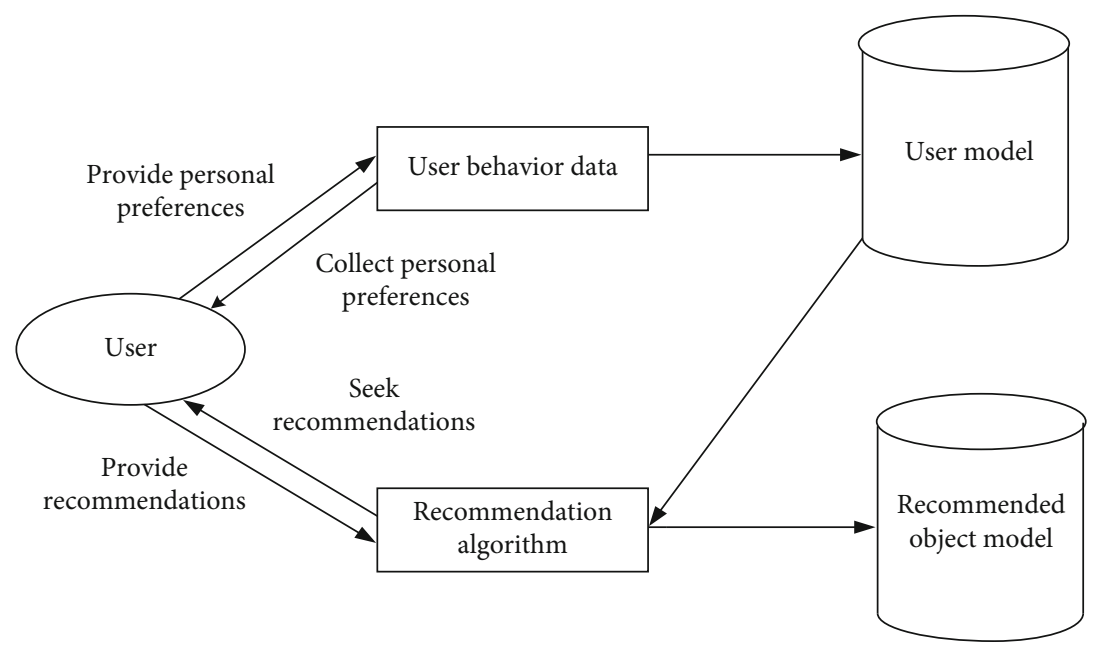

FIGURE 2: Recommendation algorithm composition.

$$
y\left(k T+t_{t}\right)=\frac{B_{i}(\delta)}{A_{i}(\delta)} \bar{u}\left(k T+t_{i}\right)+v\left(k T+t_{i}\right) .
$$

Big data ecology can be divided into three levels: microlevel core value chain, mesolevel extended value chain, and macrolevel big data ecology [19]. Among them, the core value chain is centered on the data value chain, including direct data suppliers and data value distribution channels; the extended value chain is centered on the core value chain, consisting of providers, data markets, data suppliers' suppliers, complementary data products, service providers, and direct data end users. The macrolevel big data ecosystem mainly refers to some related organizations in the periphery, such as government agencies, regulatory agencies, investors, venture capital \& incubators, industry associations, academics and research institutions, standardization organizations, start-ups, and entrepreneur groups, as well as various other competitors, stakeholders, and peripheral members. The recommendation algorithm through big data is shown in Figure 2.

For the big data ecology, the diversity of members is crucial [20]. Diversity is an ecological concept. Various organisms in the ecology play different important roles in the environment. Many complete food chains and complex food webs have been formed between species and species and between organisms and the environment. The circle constitutes a virtuous circle of material and energy flow. Once the food chain is broken, the function will not be able to perform normally. Similar to the natural ecology, diversity is also indispensable to the big data business ecology: first, the diversity of members plays a buffer role for its response to environmental uncertainty; second, the value creation of diversity on the big data business ecology is of great benefit. For example, in order to build a data-centric business ecosystem, Alibaba has successively invested or acquired many Internet companies with a large amount of high-quality data, such as Sina Weibo and Didi Chuxing. This has played a huge role in the creation of ecological value; third, diversity is a prerequisite for self-organization of the big data business ecology [21].

2.3. Machine Learning. The research object of machine learning is how to make machines have the same judgment ability and intelligence as humans. Its goal is to use various data to train machines. By improving algorithms and data structures, the machine can continuously improve its own analysis and prediction capabilities [22, 23].

The so-called machine learning is based on a lot of past and post experience for predicting problems. This type of prediction includes classification and regression problems. It is committed to solve the problem of using a lot of experience to improve the performance of the entire predictive system, so that it can successfully complete the task and meet the target requirements. Due to the huge amount of calculation required for machine learning, it is unrealistic and impractical to rely solely on people to calculate, so the help of computers is needed [24]. In computer systems, what people call "experience" is actually a set of disorganized data. What machine learning needs to do is to use algorithms to generate models from the appealed experience and then use the generative models to achieve what needs to be done.

Among the machine learning algorithms, the most widely used judgment methods are the omission method, crossvalidation method, and self-service method. The retention method is to divide the dataset into two mutually exclusive subsets, which can be combined into a whole. The two sets are divided into two parts: the verification set and the learning set. The two sets must maintain the consistency of the data distribution to prevent the introduction of additional errors and cause unnecessary errors in the final result. When the omission method is used, it needs to be used multiple times, and then, the average value of the multiple results is taken as the final result [25].

For a machine learning algorithm, in order to verify the pros and cons of the algorithm, and whether the algorithm can successfully solve people's problems, it must pass the evaluation and test of the model. Support vector machines 
can be divided into linear support vector machines and nonlinear support vector machines. The advantage of linear classification advantage is that no sample data is required. The formula is as follows:

$$
f(x)=x w^{t}+b
$$

$w$ and $b$ are obtained based on training data. For nonlinear classification, part of the support vector (sample data) is required, namely,

$$
w=\sum_{i=1}^{n} a_{i} y_{i} x_{i}
$$

Therefore, the expression of the nonlinear vector machine is

$$
f(x)=\sum_{i=1}^{n} a_{i} y_{i} K\left(x_{i}, x\right)+b .
$$

In the formula, $x_{i}$ is the training data $i, y_{i}$ is the label value of the training data $i$, and $a_{i}$ is the Langera day multiplier of the training data $i$. The kernel function is

$$
K\left(x_{1}, x_{2}\right)=\exp \left(-\frac{\left\|x_{1}-x_{2}\right\|^{2}}{2 \sigma^{2}}\right) .
$$

$a, \sigma$, and $b$ are the values generated in the training data. The $\sigma$ adjustment can match different dimensions. The smaller the value of $\sigma$, the higher the dimension. Under normal circumstances, the overall sample will be classified into two categories-one is classified correctly and the other is classified incorrectly. We call the ratio of the number of samples judged to be positive examples as negative examples to the total number of samples as the "model error rate". Once a certain point is misclassified a lot of times, the weight assigned to it will be high accordingly. Estimate a constant value and minimize the loss function, and then,

$$
f(x)=a g \min _{c} \sum_{i=1}^{n} L\left(y_{i}, c\right) .
$$

The value of the negative gradient of the current model loss function is used as the residual estimation value.

$$
r_{m i}=-\left[\frac{\partial L\left(y_{i}, f\left(x_{i}\right)\right)}{\partial f\left(x_{i}\right)}\right] f_{(x)=f_{m-1}(x)} .
$$

The advance search method is used to estimate the value of the leaf node area to minimize the loss function.

$$
f_{m}(x)=f_{m-1}(x)+\sum_{i=1}^{i} c_{m i} I\left(x \in R_{m i}\right) .
$$

Finally, we get the model that we need

$$
\bar{f}(x)=f_{M}(x)=\sum_{m=1}^{M} \sum_{i=1}^{I} c_{m i} I\left(x \in R_{m i}\right) .
$$

2.4. Design Features of Children's Products. For children, it is a very pleasurable thing to get a children's food packaging design that makes them "satisfied." Children often have corresponding dependence or emotional sustenance on some emotional and interesting small toys or small packages with interesting structures around them. Directly speaking, the psychological development of children may be affected by the quality of children's products. Designers must treat this issue with caution. By consulting relevant materials, investigating and researching small target users with meticulous and cautious methods, and testing the product many times before it can be put on the market, these are the necessary design processes for the design of children's products, as is the emotional design process for children's product packaging. Therefore, its products must have the following characteristics:

(1) It can improve children's enthusiasm for life. Innocent and lively, richly imaginative, and curious beyond ordinary people are the nature of children, and their inner world is very colorful. Every word, every graphic, and even a color block on the packaging of children's products can cause emotional changes and increase their concentration and curiosity. As children grow older, their emotional and cognitive abilities will change significantly. Designers need to pay attention not to bring negative emotions into the packaging design of children's products, let alone use adult thinking to guess children's psychological nature. Only a packaging design for children's products that is full of emotional design factors can enhance children's curiosity to explore the unknown and allow them to face life positively

Not only in the packaging design of children's products but in the entire children's products, fun is one of the indispensable features. "Education and fun" is highly praised by children's education. Therefore, the packaging design of children's products should be colorful, in fun and attractive in appearance, and can transmit knowledge.

(2) Simpler outer packaging structure compared with the complicated structure of the outer packaging structure, children's product packaging with a simple appearance structure will be very popular with children. They can easily explore the method of opening the package and can quickly and easily reconcile the packaging. The packaging generates interaction and enters a state of happily enjoying the food. The simple structure of children's product packaging can help them improve their judgment and selfconfidence and obtain a very good user experience 
from it, which can also be further improved emotionally

In summary, designers should have a correct and indepth understanding of children's emotional cognition and aesthetics, start with their operational capabilities and creativity, and combine the development trend of children's product packaging in the future society and carry out a system from the perspective of children analysis and design, combined with user experience feedback information to design children's product packaging with rich emotions and good user experience.

\section{Children's Product Packaging Preference Design Experiment}

3.1. Research Purpose. Under the circumstances of much concern, the society and the packaging of children's products have also given certain expectations. Based on ensuring the safety of children's products, it is expected that children's product packaging can incorporate more elements to improve the quality and quality of children's lives. Based on user experience, conduct in-depth research on the design of children's product packaging and try to design children's product packaging that is more suitable for children's lives and actual needs and express the potential emotional expression contained in the design language of children's product packaging design. A detailed investigation and analysis have also been carried out to provide a strong theoretical basis for this article.

3.2. Research Objects. Currently, the direct audience for children's product packages is children. However, due to the peculiarities of the children in this group, most buyers are parents or elders of the child. Therefore, the user research objects of children's product packaging should not be limited to children, but also their family members, especially their parents.

Through the in-depth investigation and analysis of children's product packaging in the early stage, we are deeply aware of the current situation of the use and demand of children's product packaging by children and their families, the latest survey results of users' purchasing needs. Through the content of the questionnaire, it is possible to analyze the problems existing in the packaging of children's products and the trend of user demand. The content of the questionnaire roughly includes how users choose children's product packaging and their expectations for future children's product packaging design.

3.3. Determine the Evaluation Weight. The index weight is a numerical index indicating the importance and function of the index. In the indicator system of the evaluation plan, the weight of each indicator is different. Even if the indicator level is the same, the weight is different. Index weight is also called weight and is usually represented by $a$. It is a number greater than zero but less than 1 , and the sum of the weights of all first-level indicators must be equal to 1 , that is, satisfying the conditions $0<a<1$ and $\sum a-1$.
3.4. Statistics. All data analyses in this article use SPSS19.0, the statistical test uses the two-sided test, significance is defined as 0.05 , and $p<0.05$ is considered significant. The statistical results are displayed as mean \pm standard deviation $(x \pm \mathrm{SD})$. When the test data obeys the normal distribution, the double $t$-test is used for comparison within the group and the independent sample $t$-test is used for comparison between the groups. If the regular distribution is not sufficient, two independent samples and two related samples will be used for inspection.

\section{Analysis of the Preference Design of Children's Product Packaging}

4.1. Children's Color Preferences. The use of appropriate colors in children's packaging can accurately convey the information of the product and prompt consumers to buy the product in the end. Through the investigation of children, the age and color hobbies of children based on the investigation and research are shown in Table 1.

It can be seen in Table 1 that children in early childhood like bright colors, especially colors with strong contrast and some children's love for bright colors can continue until elementary school. Among preschoolers, the three favorite colors of boys are blue, yellow, and orange and those suitable for girls are yellow, orange, and red. After entering school age after six years old, the colors that boys and girls like gradually have their own personalities. School-age boys like orange, yellow, and light-blue. Girls like very light green and orange. Therefore, when using product packaging colors, it is necessary to conduct research on consumer groups and design color packaging suitable for this group of people. In order to verify the correctness of the results, we surveyed 200 children and obtained relevant data, as shown in Figure 3.

It can be seen in Figure 3 that the results of the experiment are basically consistent with the data and the true validity of the data can be determined. Consumers of children's products are mainly children's parents, but their personalities and environments are different, and their consumption habits are also different. Therefore, we have made statistics on the purchase of children's products by parents, as shown in Table 2.

In Table 2, we can see that when parents buy products for children, the main reason is that they feel that the products are good for children's development, followed by children who want to buy and go shopping in the mall. This shows that contemporary young parents also tend to consume more rationally.

4.2. Children Choose Preferences. We have carried out statistics on children's preferences on toys and show children's preferences for different toys through the difference of educational toys. The specific toy choices are shown in Table 3:

We collect statistics on children's preferences for these five types of toys at different ages and quantify their preferences for easy comparison. The results are shown in Figure 4. 
TABLE 1: Children's color preference.

\begin{tabular}{lcccccc}
\hline Age ranking & Gender & 1 & 2 & 3 & 4 & 5 \\
\hline \multirow{2}{*}{ Early childhood (2-6 years old) } & Male & Blue & Yellow & Orange & Powder & - \\
& Female & Yellow & Orange & Red & Purple & Yellow-green \\
\hline \multirow{2}{*}{ School age (6-12 years old) } & Male & Orange & Yellow & Blue-green & Yellow-green & White \\
& Female & Light green & Orange & Yellow & Canary & White \\
\hline
\end{tabular}

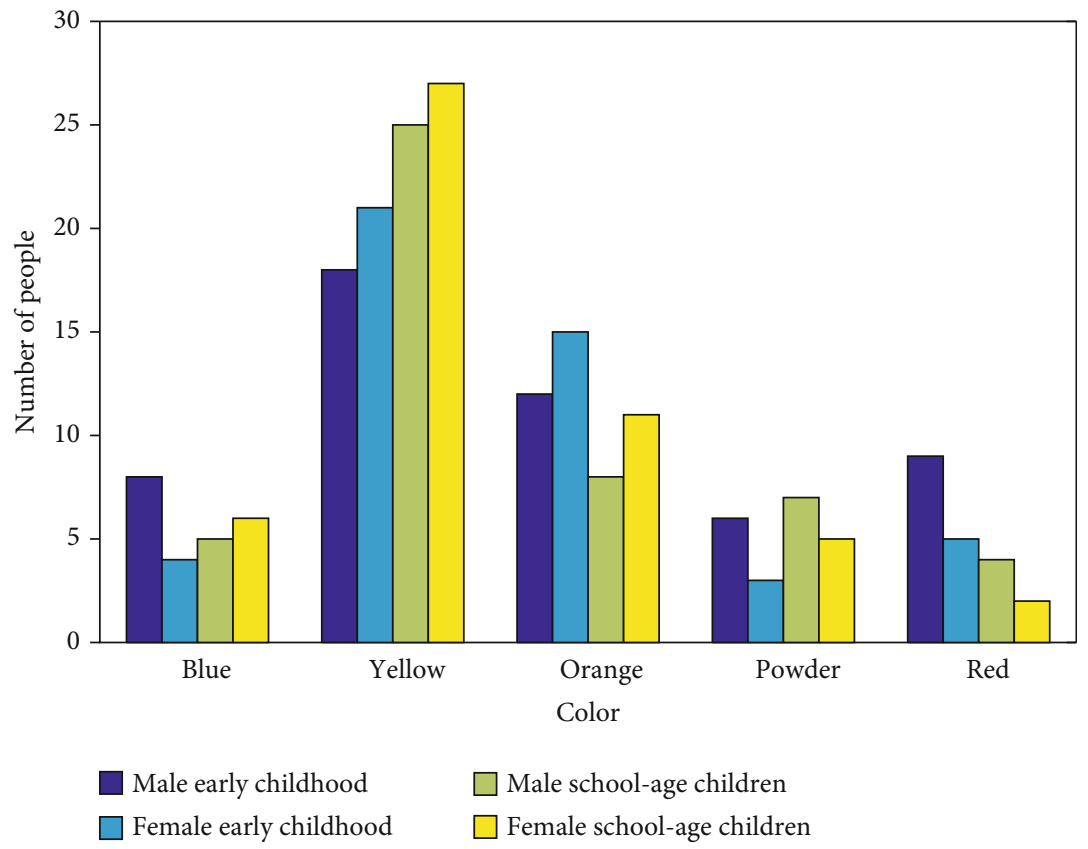

Figure 3: Trends in children's product selection.

TABle 2: Parents' purchase of children's products.

\begin{tabular}{lc}
\hline Options & Proportion (\%) \\
\hline Child requirements & 15.92 \\
Feel good for development & 50.03 \\
Other children playing & 3.81 \\
Children birthday & 8.8 \\
Holidays & 6.6 \\
Introduction & 1.01 \\
Advertising & 1.05 \\
Random to see & 12.4 \\
\hline
\end{tabular}

In Figure 4, we can see that children of different grades have different preferences for toys. On the whole, preschool-age children prefer educational toys and maze toys, while school-age children prefer construction toys. This is also due to the nature of the children. We combine colors and types of toys to investigate their attractiveness to children. The attractiveness to children is shown in Figure 5.

It can be seen in Figure 5 that children's preference for red toys is higher than other colors and yellow toys are the least attractive to children and the gap between the two is
Table 3: Preference materials for the selection of educational toys.

\begin{tabular}{lcc}
\hline Toy number & Class concept & Specific toys \\
\hline 1 & Building class & Building blocks \\
2 & Puzzles & Animal jigsaw \\
3 & Pairing & Number letter \\
4 & Rubik's cube & Rubik's cube \\
5 & Labyrinth & Planar magnet maze \\
\hline
\end{tabular}

more than $30 \%$. This shows that, for children, the production of products according to different colors can well grasp the preferences of children and increase the sales volume of the company. Of course, the way parents and children think is not the same. If companies want to increase sales, they must not only target children but also understand the parents' thoughts. Therefore, we have also conducted relevant surveys on parents' preferences for children's products, as shown in Figure 6.

In Figure 6, we can see that there is a certain difference between parents and children's preferences for colors and materials. When companies produce children's products, they need to conduct related investigations on the 




FIGURE 4: Children's preferences for toys of different ages.

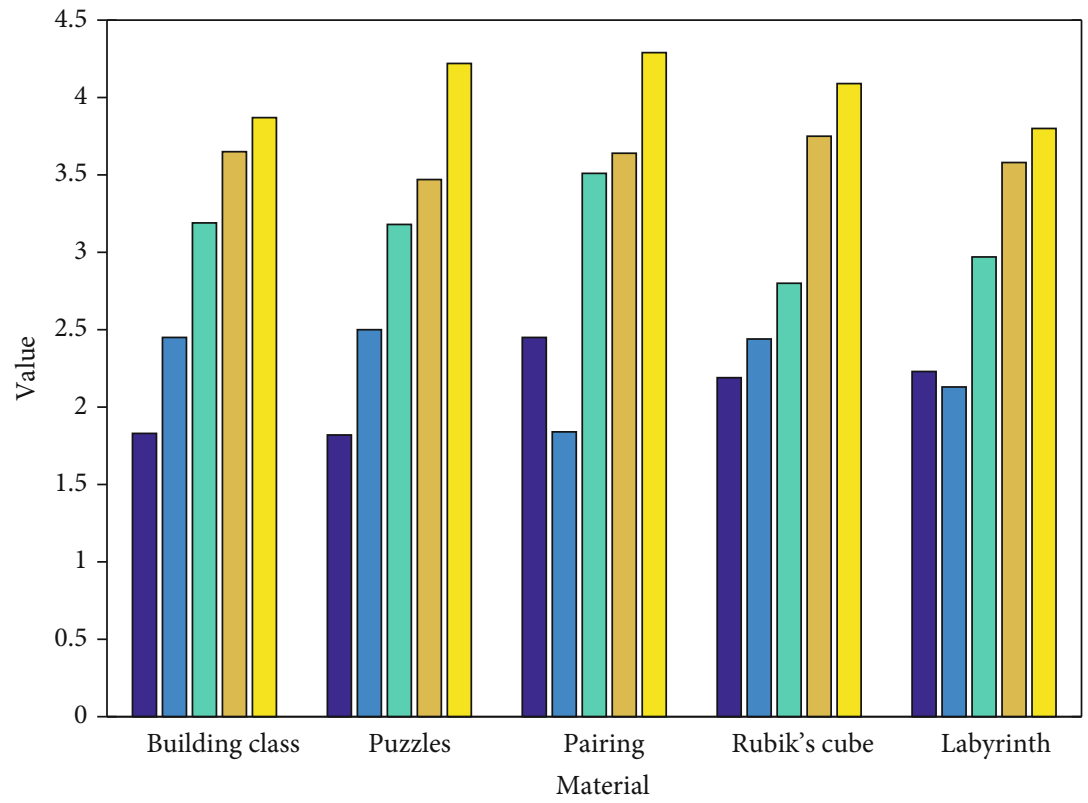

Blue $\square$ Powder

$\square$ Yellow $\quad \square$ Red

$\square$ Orange

FIGURE 5: Male children's preference for different colors of toys. 


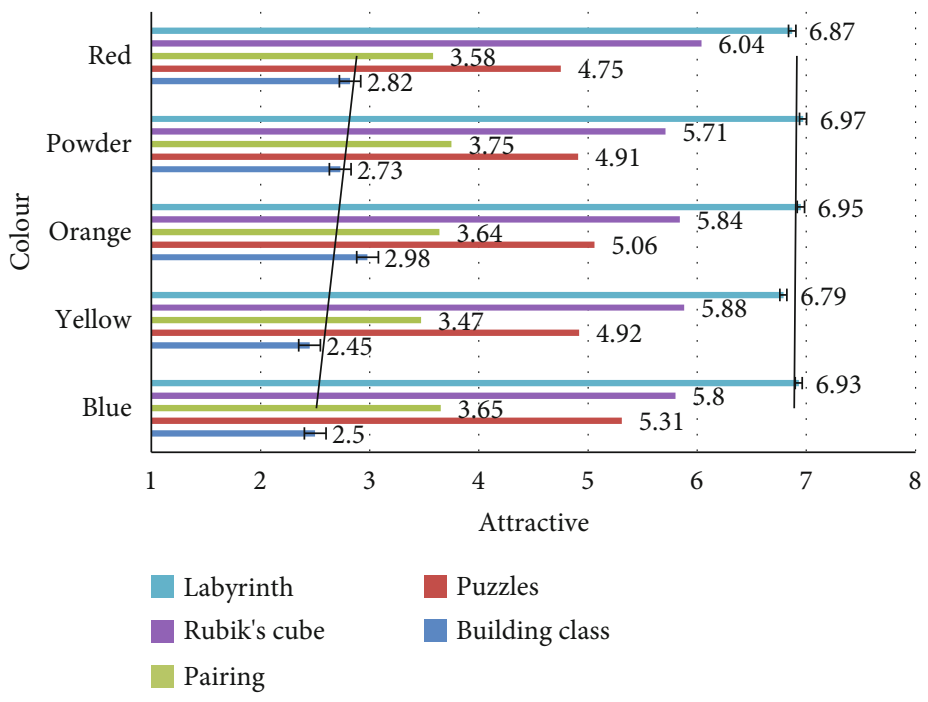

FIgURE 6: Parents' preference for children's products.

preferences of parents and children to clarify the target customers of their products, good to increase product sales.

\section{Conclusion}

Modern children's product packaging design is a comprehensive design subject art, and it is no longer a simple packaging design application. Related aspects include surface modeling art, material art, text, and graphic design art. The psychological effects and humanity and cultural implications of the packaging itself radiate from within the product itself. This article takes child consumers as the main target and starts from how the emotional design of children's product packaging can more successfully enhance the user experience. Transform the current children's product packaging that lacks emotional color and interactivity into an emotional packaging design for the purpose of satisfying children's user experience. There are also some shortcomings in the research of this paper. In the research, there is not too much attention to the application of green packaging in the emotional design of children's products and there is a problem of low attention to the packaging of children's green products. The user experience design in children's product packaging has not been fully developed, and some entry points are still very vague. It is necessary to increase the study and work in the future and work hard to research and propose better solutions.

\section{Data Availability}

The data that support the findings of this study are available from the corresponding author upon reasonable request.

\section{Conflicts of Interest}

The author declares that they have no conflicts of interest.

\section{Acknowledgments}

This work was supported by the 2018 General Project of Humanities and Social Science Research of the Ministry of Education: "A Study on the Relationship between Images of Ming Dynasty Relics and Literature" (project approval no.: 18YJC760135). This work was supported by Suzhou University 2020 university-level quality engineering project online and offline mixed course "New Media Advertising Design" (project no.: szxy2020hhkc03).

\section{References}

[1] Z. Wang, Q. Ma, H. Bai, Q. Zhang, Y. Cai, and Q. Lv, "Migration regularity of six preservatives from wooden children's products to saliva and sweat based on microstructure-related migration models," Ecotoxicology and Environmental Safety, vol. 173, pp. 149-155, 2019.

[2] S. K. Murnen, C. Greenfield, A. Younger, and H. Boyd, "Boys act and girls appear: a content analysis of gender stereotypes associated with characters in children's popular culture," Sex Roles, vol. 74, no. 1-2, pp. 78-91, 2016.

[3] D. Y. Kim, S. H. Chun, Y. Jung et al., "Phthalate plasticizers in children's products and estimation of exposure: importance of migration rate," International Journal of Environmental Research and Public Health, vol. 17, no. 22, pp. 8582-8584, 2020.

[4] M. Li, R. Li, Z. Wang, Q. Zhang, H. Bai, and Q. Lv, "Optimization of headspace for GC-MS analysis of fragrance allergens in wooden children's products using response surface methodology," Separation Science Plus, vol. 2, no. 1, pp. 26-37, 2019.

[5] A. R. Popa, "Advertisements for children's products in women's magazines: traits of the discourse," Gender Studies, vol. 17, no. 1, pp. 94-104, 2018.

[6] L. Rosana, H. Silva, and R. M. Gomes, "Evaluation of the presence of allergens in children's products available for sale in a big city," Anais Brasileiros de Dermatologia, vol. 93, no. 3, pp. 457-459, 2018.

[7] C. H. Basch, A. Kecojevic, V. Cadorett, and C. E. Basch, "Advertisements for children's entertainment products in a 
popular parenting magazine: sedentary or active?," Health Promotion Perspectives, vol. 7, no. 1, pp. 47-49, 2017.

[8] M. A. Silva, L. C. Milagres, A. P. Castro et al., "O consumo de produtos ultraprocessados está associado ao melhor nível socioecocômico das famílias das crianças," Ciencia \& Saude Coletiva, vol. 24, no. 11, pp. 4053-4060, 2019.

[9] L. A. Fletcher, T. Pham, M. Herriman, B. Kiely, R. Milanaik, and G. A. Rosner, "Peanut-containing products in children's hospitals: putting pediatric patients at risk," Journal of Allergy and Clinical Immunology, vol. 137, no. 2, pp. 78-85, 2016.

[10] J. L. Pomeranz and J. L. Harris, "Children's fruit "juice” drinks and FDA regulations: opportunities to increase transparency and support public health," American Journal of Public Health, vol. 110, no. 6, pp. e1-e10, 2020.

[11] G. Gary, G. Justine, and F. Brenda, “Approaches to children's exposure assessment: case study with diethylhexylphthalate (DEHP)," International Journal of Environmental Research \& Public Health, vol. 13, no. 7, pp. 670-673, 2016.

[12] Z. Mchome, S. Yousefzadeh, A. Bailey, and H. Haisma, "“When I breastfeed, it feels as if my soul leaves the body": maternal capabilities for healthy child growth in rural Southeastern Tanzania," International Journal of Environmental Research and Public Health, vol. 17, no. 17, pp. 6215-6522, 2020.

[13] S. Demiral, "Considering discourse with children through animations," International Journal of Pedagogy Innovation and New Technologies, vol. 7, no. 2, pp. 47-57, 2020.

[14] A. Z. Teixeira, "Sodium content and food additives in major brands of Brazilian children's foods," Ciencia \& saude coletiva, vol. 23, no. 12, pp. 4065-4075, 2018.

[15] A. Anwar, P. M. Abruzzo, S. Pasha et al., "Advanced glycation endproducts, dityrosine and arginine transporter dysfunction in autism - a source of biomarkers for clinical diagnosis," Molecular Autism, vol. 9, no. 1, pp. 3-10, 2018.

[16] W. L. Yuan, N. Rigal, S. Monnery-Patris et al., "Early determinants of food liking among 5y-old children: a longitudinal study from the EDEN mother-child cohort," International Journal of Behavioral Nutrition \& Physical Activity, vol. 13, no. 1, pp. 20-25, 2016.

[17] S. Beckwith, "Feeding the baby products supply chain," Inbound logistics, vol. 39, no. 6, pp. 67-70, 2019.

[18] S. I. Lee and C. H. Kim, "A study of consideration of children's furniture design elements," Journal of the Korea furniture Society, vol. 28, no. 3, pp. 185-197, 2017.

[19] S. H. Min, "Study on recognition and consumption behavior of quality-certified children's preferred foods of nursery directors and parents in Jecheon area," Korean Journal of Food and Cookery Science, vol. 33, no. 3, pp. 353-362, 2017.

[20] F. Bellisle, P. Hébel, A. Salmon-Legagneur, and F. Vieux, "Breakfast consumption in French children, adolescents, and adults: a nationally representative cross-sectional survey examined in the context of the International Breakfast Research Initiative," Nutrients, vol. 10, no. 8, pp. 1056-1059, 2018.

[21] S. M. Ng, J. C. Agwu, and K. Dwan, "A systematic review and meta-analysis of synacthen tests for assessing hypothalamicpituitary-adrenal insufficiency in children," Archives of Disease in Childhood, vol. 101, no. 9, pp. 847-853, 2016.

[22] J. Gómez-Paredes, A. Alsamawi, E. Yamasue et al., "Consuming childhoods: an assessment of child labor's role in Indian production and global consumption," Journal of Industrial Ecology, vol. 20, no. 3, pp. 611-622, 2016.

[23] F. P. Perera, K. Wheelock, Y. Wang et al., "Combined effects of prenatal exposure to polycyclic aromatic hydrocarbons and material hardship on child ADHD behavior problems," Environmental Research, vol. 160, pp. 506-513, 2018.

[24] C. Mei-Ju, "Board games play matters: a rethinking on children's aesthetic experience and interpersonal understanding," Eurasia Journal of Mathematics Science \& Technology Education, vol. 13, no. 6, pp. 2405-2421, 2017.

[25] V. R. Kuchma, L. M. Sukhareva, M. I. Stepanova, P. I. Chramtsov, I. E. Aleksandrova, and S. B. Sokolova, "Scientific bases and technologies of security hygienic safety of children in the digital school," Gigiena i Sanitariia, vol. 98, no. 12, pp. 13851391, 2019. 